\title{
The relationship between semen evaluation methods and fertility in the bull
}

\author{
Eileen Linford, F. A. Glover, * C. Bishop* and D. L. Stewart \\ Cattle Breeding Centre, Ministry of Agriculture, Fisheries and Food, Shinfield, \\ Reading, RG2 9BZ, Berkshire and *National Institute for Research in Dairying, \\ Shinfield, Reading, RG2 9AT, Berkshire, U.K.
}

\begin{abstract}
Summary. The results are presented of two experiments in which the quality of samples of bull semen was assessed by a number of laboratory tests and then correlated with the 112-day non-return percentage obtained by the use of those samples in A.I. The results reveal the inadequacy of the laboratory tests used as methods of predicting the fertility of semen samples but show that limits may be set outside which poor semen samples could be discarded.
\end{abstract}

\section{Introduction}

Laboratory methods of evaluation of bovine semen are used currently to select bulls for artificial insemination and to select semen ejaculates of a satisfactory standard from bulls at A.I. centres. It is essential, therefore, to quantify the relationship between the various laboratory methods of semen evaluation and the fertility obtained by the use of that semen. Bishop, Campbell, Hancock \& Walton (1954) investigated this relationship at 4 insemination centres using 168 ejaculates from 76 bulls of 7 breeds. Since that time, there have been changes in commercial A.I. technology, the most important of which is the freezing of bull semen in polyvinyl chloride straws and the reduction in the number of spermatozoa per insemination whereby a larger number of inseminations per ejaculate has been achieved. By contrast, there have been few changes in the methods of semen evaluation. It seemed appropriate at this time to re-examine the correlation of bull semen characteristics with fertility.

The results presented here are from two experiments. The first experiment was designed to compare the correlation of semen evaluation methods with fertility when either fresh or frozen semen was used (Stewart, O'Hagan \& Glover, 1972). Semen used in this experiment was collected from bulls used routinely at Reading in the commercial A.I. service. The limited range of non-return data obtained in this experiment was the result of using semen from a small group of regular bulls. Therefore a second experiment was designed in which a large number of frozen semen samples was used from bulls with a wider range of fertilities. Some of these bulls, by their semen characteristics alone, would not have been acceptable according to current practice for commercial A.I.

\section{Materials and Methods}

\section{Semen}

Experiment 1. Semen was collected on five occasions from each of 5 Friesian bulls. The samples used were of a single ejaculate or occasionally of pooled ejaculates and provided semen for a minimum of 160 inseminations. Semen samples were then divided into two for use in the liquid or frozen form, both of which were dispensed in $0 \cdot 5-\mathrm{ml}$ capacity polyvinyl chloride straws each containing a total of about $20 \times 10^{6}$ spermatozoa, including dead and live cells. Samples were diluted for use as liquid semen in $92.5 \%(\mathrm{v} / \mathrm{v})$ ultra-heated (UHT) skim milk, $6.0 \%(\mathrm{v} / \mathrm{v})$ egg yolk, $1.5 \%(\mathrm{v} / \mathrm{v})$ glycerol, 500 i.u. penicillin $/ \mathrm{ml}$ and $500 \mu \mathrm{g}$ streptomycin sulphate $/ \mathrm{ml}$ and stored for approximately $24 \mathrm{hr}$ at $5{ }^{\circ} \mathrm{C}$ before use. Semen to be frozen in liquid nitrogen was diluted in $83.0 \%(\mathrm{v} / \mathrm{v})$ UHT skim milk, $10.0 \%$ 
$(\mathrm{v} / \mathrm{v})$ egg yolk, $7 \cdot 0 \%(\mathrm{v} / \mathrm{v})$ glycerol, to which was added $12.5 \mathrm{mg}$ fructose $/ \mathrm{ml}, 500$ i.u. penicillin $/ \mathrm{ml}$ and $500 \mu \mathrm{g}$ streptomycin sulphate $/ \mathrm{ml}$.

Experiment 2. Five semen samples from each of 24 bulls ( 13 Friesian, 7 Hereford, 2 Jersey and 2 Charolais) were diluted with $83.0 \%$ (v/v) UHT skim milk, $10.0 \%$ (v/v) egg yolk, $7 \cdot 0 \%$ (v/v) glycerol, to which was added $12.5 \mathrm{mg}$ fructose $/ \mathrm{ml}, 500$ i.u. penicillin $/ \mathrm{ml}$ and $500 \mu \mathrm{g}$ streptomycin sulphate $/ \mathrm{ml}$. The diluted semen was dispensed in $0.5-\mathrm{ml}$ straws and frozen $4 \mathrm{~cm}$ above liquid nitrogen. Each straw contained about $20 \times 10^{6}$ spermatozoa and was stored for at least 28 days at $-196^{\circ} \mathrm{C}$. A minimum of 200 inseminations per semen sample was achieved.

\section{Inseminations}

The semen was used only for first inseminations in Exp. 1 and for first and repeat inseminations in Exp. 2. These inseminations were carried out by the Reading Centre and the Guildford, Banbury and Faringdon Sub-Centres. The percentage of cows not returning for a repeat insemination (non-return) at 112 days after the insemination date was recorded and used as the measure of the fertility of a semen sample.

\section{Semen evaluation methods}

Test $A$. Sperm motility (vigour of the wave motion) was subjectively scored by two observers using a scale of 0 to 5 . The undiluted and coded semen samples were examined in a microscope with a heated stage maintained at $40^{\circ} \mathrm{C}$.

Test $B$. As in Test A, but a scale of 0 to 10 was used.

Test $C$. The proportion of spermatozoa (expressed as a percentage) showing progressive motility at $40^{\circ} \mathrm{C}$ after a 20 -fold dilution of a semen sub-sample in $0.9 \%(\mathrm{w} / \mathrm{v}) \mathrm{NaCl}$ was subjectively assessed.

Test $D$. The motility of the spermatozoa in undiluted semen was objectively measured by means of the Motility Meter (Glover, 1968) which is based on an optical-rheological principle; shearing forces are imposed on the semen to erase the pattern of movement, the wave pattern of the sperm movement gradually returns when these forces are removed and the reciprocal of the time taken for the return of movement is recorded as motility.

Test $E$. The percentage of 'dead' spermatozoa in undiluted semen, i.e. those cells stained by a nigrosin-cosin stain (Hancock, 1956), was subjectively assessed.

Test $F$. The percentage of morphologically abnormal spermatozoa was subjectively assessed using the slides prepared for Test $\mathrm{E}$. The abnormal spermatozoa were further classified as follows: (i) abnormal heads; (ii) detached heads; (iii) cytoplasmic droplets attached to the anterior part of the midpiece; (iv) cytoplasmic droplets attached to the middle part of the mid-piece; (v) cytoplasmic droplets attached distally; (vi) coiled tails; (vii) bent tails; and (viii) other abnormalities.

Test $G$. The percentage of motile spermatozoa in semen thawed for at least $24 \mathrm{hr}$ after freezing was assessed by two observers.

Test $H$. As for Test G, but assessment after $1 \mathrm{hr}$ of incubation of the thawed semen shaken in a water bath at $40^{\circ} \mathrm{C}$.

Test I. As for Test $\mathrm{H}$ after $2 \mathrm{hr}$ of incubation.

Test $J$. The amount of glutamic-oxaloacetic transaminase (GOT) in the seminal plasma of undiluted semen was measured spectrophotometrically. This assay indicated the extent of membrane damage of the spermatozoa and was carried out on 53 of the semen samples only.

Test $K$. As for Test $\mathrm{J}$ but on the thawed, diluted semen samples.

Test $L$. For 114 of the semen samples the heat of metabolism of spermatozoa in thawed, diluted samples was measured on an LKB model 10700-1 microcalorimeter by Dr N. J. Berridge (Department of Chemical Microbiology, National Institute for Research in Dairying, Shinfield, Reading).

Test $M$. Six of the semen samples were sub-sampled by Dr R. C. Jones (now at Department of Biological Sciences, University of Newcastle, New South Wales, Australia) to determine aberrations of the ultrastructure of the spermatozoa after cooling and freezing. Nine morphological classes of 
spermatozoa were distinguished according to the presence or absence of ultrastructural features of the plasma membrane and acrosome (see Jones \& Martin, 1973).

\section{Results}

\section{Experiment 1}

The distribution of the non-return data obtained by use of fresh semen (mean $63 \cdot 7$, standard deviation 7.0) was similar to that of frozen semen (mean 62.8, standard deviation $7 \cdot 7$ ) even though the number of samples in each category was small (Text-fig. 1). The degree of the relationship between the non-return rate at 112 days after insemination and each of the 8 evaluation tests has been expressed as a correlation coefficient, the percentage of variation of the non-return rate accounted for by each test and the $95 \%$ confidence limits of the predicted non-return value of a single sample (Table $1 \mathrm{a}$ and b). None of the correlation coefficients was high. Test $\mathrm{H}$, the post-thaw $\%$ motility after incubation at $40^{\circ} \mathrm{C}$ for $1 \mathrm{hr}$, and Test $\mathrm{D}$, the motility meter reading at collection, gave correlation coefficients significantly different from zero $(P<0.05)$ for fresh and frozen semen respectively. However, the rank order of the tests in respect of correlation was not the same for fresh and frozen semen. None of the tests could be used for a fresh or frozen semen sample to predict a non-return value with $95 \%$ confidence limits less than $\pm 12 \cdot 7 \%$ (Table $1 \mathrm{a}$ and $\mathrm{b}$ ).

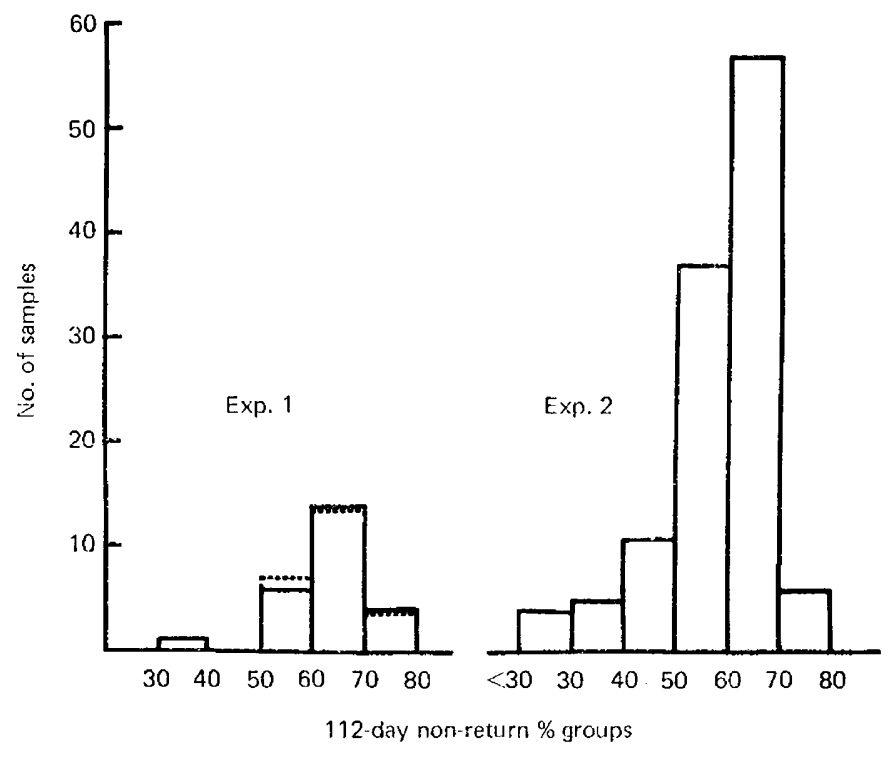

Text-fig. 1. Distribution of the 112-day non-return percentages obtained by the use of bovine semen samples (----, fresh; - - , frozen) in Experiments 1 and 2.

\section{Experiment 2}

In comparison with the results of Exp. 1, the distribution of non-return data in this experiment (mean 57.9, standard deviation 10.7) showed a larger number of samples in each category, particularly those of less than $50 \%$ non-return (Text-fig. 1). A diagram showing the relationship between the nonreturn rate and Test $G$ (the post-thaw motility of spermatozoa) is presented in which each semen sample is distinguished by the breed of the bull from which it was collected (Text-fig. 2). Test $G$ is that most commonly used to evaluate bull semen after processing. An analysis of variance of the nonreturn data showed that there were significant differences in the non-return rate between bulls of the 
Table 1. Relationship between non-return percentages and evaluation tests for bovine semen

\begin{tabular}{ccc}
\hline & & \\
Correlation & $\%$ Variation accounted & $95 \%$ Confidence limits \\
coefficient $(r)$ & for in non-return $\left(100 r^{2}\right)$ & of a single sample \\
\hline
\end{tabular}

(a) Exp. 1, fresh semen

\begin{tabular}{|c|c|c|c|}
\hline $\mathbf{H}$ & $+0.412^{*}$ & $17 \cdot 0$ & $12 \cdot 7$ \\
\hline I & +0.377 & $14 \cdot 2$ & $13 \cdot 0$ \\
\hline $\mathrm{G}$ & +0.351 & $12 \cdot 3$ & $13 \cdot 1$ \\
\hline C & +0.312 & $9 \cdot 7$ & $13 \cdot 1$ \\
\hline E & +0.295 & $8 \cdot 7$ & $13 \cdot 1$ \\
\hline$F$ & +0.179 & $3 \cdot 2$ & $13 \cdot 5$ \\
\hline A & +0.158 & $2 \cdot 5$ & $13 \cdot 6$ \\
\hline D & +0.094 & 0.9 & $13 \cdot 7$ \\
\hline
\end{tabular}

(b) Exp. 1, frozen semen

\begin{tabular}{|c|c|c|c|}
\hline D & $+0.408^{*}$ & $16 \cdot 6$ & $13 \cdot 6$ \\
\hline $\mathbf{E}$ & +0.335 & $11 \cdot 2$ & $14 \cdot 3$ \\
\hline $\bar{G}$ & +0.253 & 6.4 & 14.9 \\
\hline $\mathbf{H}$ & +0.226 & $5 \cdot 1$ & $15 \cdot 0$ \\
\hline C & +0.222 & 4.9 & $14 \cdot 8$ \\
\hline $\mathrm{F}$ & -0.215 & $4 \cdot 6$ & 14.8 \\
\hline I & +0.158 & $2 \cdot 5$ & $15 \cdot 2$ \\
\hline A & +0.080 & $0 \cdot 6$ & $15 \cdot 1$ \\
\hline \multicolumn{4}{|c|}{ c) $\operatorname{Exp} .2$} \\
\hline C & $+0.698^{* * *}$ & $48 \cdot 7$ & $15 \cdot 1$ \\
\hline B & $+0.672^{* * *}$ & $45 \cdot 2$ & $15 \cdot 5$ \\
\hline $\mathbf{E}$ & $-0 \cdot 666^{* * *}$ & $44 \cdot 4$ & $15 \cdot 7$ \\
\hline A & $+0.641^{* * *}$ & $41 \cdot 1$ & $16 \cdot 1$ \\
\hline D & $+0.608 * * *$ & $37 \cdot 0$ & $16 \cdot 9$ \\
\hline $\mathrm{F}$ & $-0.604^{* * *}$ & 36.5 & 16.9 \\
\hline G & $+0.596^{* * *}$ & $35 \cdot 5$ & 16.9 \\
\hline $\mathbf{L}$ & $+0.548 * * *$ & $30 \cdot 0$ & $17 \cdot 1$ \\
\hline $\mathrm{H}$ & $+0.472 * * *$ & $22 \cdot 3$ & $18 \cdot 6$ \\
\hline $\mathbf{J}$ & $-0.443^{* * *}$ & $19 \cdot 6$ & $18 \cdot 6$ \\
\hline I & $+0-350^{* * *}$ & $12 \cdot 3$ & $19 \cdot 8$ \\
\hline $\mathbf{K}$ & +0.002 & 0 & $21 \cdot 0$ \\
\hline
\end{tabular}

Degrees of freedom for correlation coefficients were 23 for $(a)$ and $(b)$ and 118 for $(c)$. Significance levels: ${ }^{*} P<0.05 ;{ }^{* *} P<0.001$.

same breed $(P<0.001)$. The variation between bulls was such that significant differences in nonreturn rate between breeds could not be established. Nevertheless, of the 20 semen samples that gave a non-return rate of $<50 \%, 13$ samples were from 3 Hereford bulls. An analysis of variance was also performed for the semen evaluation tests when, in all except Test $K$ (the amount of GOT in thawed samples), there were highly significant differences in semen characteristics between bulls of the same breed $(P<0.001)$. Significant breed differences were established at a significance level of at least $P<0.05$, mainly between the Friesians and Herefords, for tests measuring motility or the extent of abnormality of the sperm head but also between the Hereford and Jersey breeds, particularly for the subjective assessment of motility in thawed semen (Tests G, $\mathrm{H}$ and I).

It appears from Text-fig. 2 that the non-return rate was positively correlated with the post-thaw motility of semen samples. There was some indication of a curvilinear relationship but the number of samples in the lower range of non-return was too small to establish such a relationship with confidence. The correlation coefficients for all the tests used are presented in Table 1(c). The coefficients were higher than in Exp. 1 and all but one were highly significant $(P<0.001)$. The improvement in the correlation was mainly due to 10 samples with low motility and low non-return rates.

A linear regression analysis of the data showed that the best single test was the subjective evaluation of sperm motility after the semen had been diluted in $0.9 \% \mathrm{NaCl}$ (Test $\mathrm{C}$ ). The relationship between the non-return rate and this test is shown in Text-fig. 3. The next best single test was another 


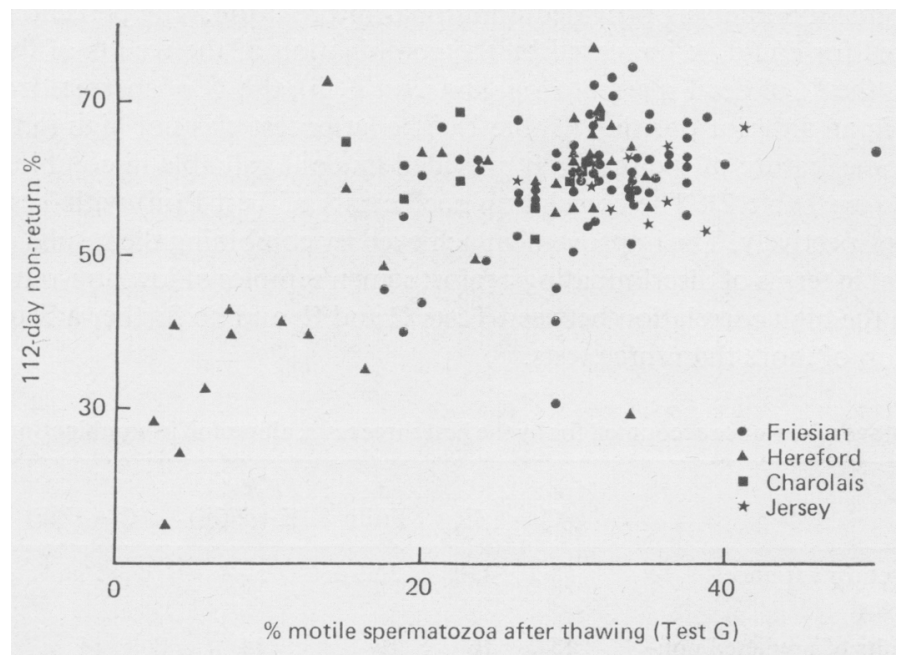

Text-fig. 2. A diagram of the association between the 112-day non-return percentage of a sample of bovine semen and the percentage of motile spermatozoa in it after thawing (Test G). Each sample is distinguished by the breed of bull from which it was collected.

means of measuring sperm motility, Test B. Apart from motility the next most reliable characteristic of semen for non-return evaluation was the \% of dead cells (Test E). The other two methods of motility measurement (Tests $A$ and $D$ ) followed Test $E$ in rank-order. All these tests were correlated with each other. The correlation coefficient of Test $C$ was +0.94 with Test $B,-0.81$ with Test $E,+0.91$ with Test $A$ and +0.78 with Test $D$. Test $D$ was the only objective method of motility measurement used in the experiment.

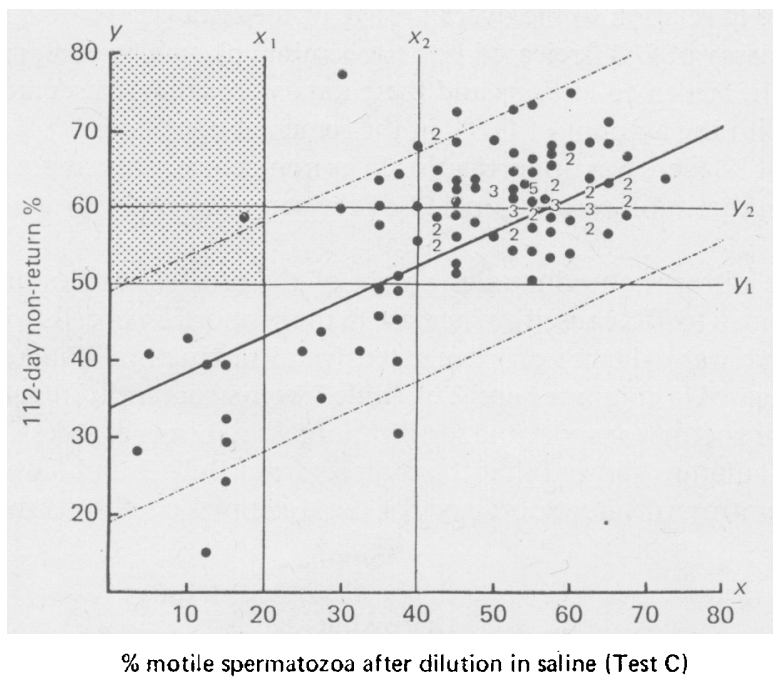

Text-fig. 3. The relationship between the 112-day non-return percentage and the percentage of motile spermatozoa in bovine semen diluted with saline (Test C). The regression line (-) and $95 \%$ confidence limits (---) for predicted non-return rate of a single sample are shown. Numbers represent tho locations at which more than one point occurs. 
A multiple regression analysis provided additional information. The percentage of non-return variance accounted for could be increased by the combination of the results of two tests; the best pair being Test $\mathrm{E}$, the $\%$ of dead spermatozoa, and Test $\mathrm{F}$ (iii), the \% of spermatozoa carrying cytoplasmic droplets in an anterior position (Table 2). The latter test was not high in the rank-order of single tests but some feature of the results it provided made it valuable in combination with either Test $\mathbf{E}$ or Test $\mathrm{C}$ (see Table 2). The correlation coefficients of Test $\mathrm{F}(\mathrm{iii})$ with Tests $\mathrm{C}$ and $\mathrm{E}$ were -0.28 and +0.17 respectively. The improvement achieved by combining the results of Tests $C, E$ and $\mathrm{F}$ (iii) was marginal in terms of discriminating against semen samples of low non-return rate, as might be expected from the high correlation between Tests $\mathrm{C}$ and $\mathrm{E}$, and no further advantage was gained by the combination of more than three tests.

Table 2. The percentage of variance accounted for by the best three tests, alone and in combinations, for bovine semen

\begin{tabular}{lcccccc}
\hline & C & E & F(iii) & E + F(iii) & C + F(iii) & E + F(iii) + C \\
\hline $\begin{array}{l}\text { Percentage of non-return variance } \\
\text { accounted for by test }\end{array}$ & $48 \cdot 3$ & $43 \cdot 8$ & $22 \cdot 3$ & $57 \cdot 4$ & $56 \cdot 5$ & $60 \cdot 5$ \\
$\begin{array}{l}95 \% \text { Confidence limits of predicted non- } \\
\text { return value of a single sample }\end{array}$ & 15 & 16 & 19 & 14 & 14 & 13 \\
\hline
\end{tabular}

The results of this study showed that although the tests were correlated with non-return rate they were of limited value as a means of predicting that rate. For the best combinations of two tests the following equations have been computed from which a non-return rate may be estimated:

$$
\begin{array}{r}
\text { non-return rate }=-0.42\{\mathrm{E}\}-1.32\{\mathrm{~F}(\mathrm{iii})\}+78.2 \\
\text { or } \\
0.44\{\mathrm{C}\}-1.06\{\mathrm{~F}(\mathrm{iii})\}+40.9
\end{array}
$$

Thus, if after testing a semen sample we predict a non-return rate of $57.5 \%$ (the mean value of these data), we estimate that, with probability 0.95 , the actual non-return rate will fall between $71.5 \%$ and $43.5 \%$ (the $95 \%$ confidence interval of the predicted non-return value of a single sample). The value of these regression equations in predicting non-return rate is clearly limited because the confidence intervals are very wide in relation to the overall range of the data $(15.0 \%$ to $77 \cdot 2 \%)$.

Tests $\mathrm{J}$ and $\mathrm{K}$, the assay of GOT released into the seminal plasma by damaged spermatozoa, were carried out on 53 of the semen collections and these data were analysed separately. The non-return rate correlated well with the amount of GOT in the semen at ejaculation $(r=-0.443)$ but after the semen was frozen (Test $K$ ) there was no correlation. The non-return rate was positively correlated with the heat of sperm metabolism measured on 114 of the semen samples by calorimetry, Test $\mathrm{L}$ ( $r=$ $+0 \cdot 548$ ).

The results of the ultrastructural studies on six of the semen samples are shown in Table 3 . Cooling the diluted semen to $5^{\circ} \mathrm{C}$ caused an increase in the proportion of cells with swollen acrosomes and after freezing there was evidence of more extensive ultrastructural damage to the sperm head. The spermatozoa indicated in columns 1 and 2 of Table 3 were structurally intact and contained all the organelles required for sperm transport and fertilization. As a means of assessing fertility, therefore, the sum of these two columns showed that the samples from Bulls 3 and 6 were not as good as the other samples. The non-return values obtained for these samples confirmed this prediction.

\section{Discussion}

One of the aims of this study was to determine if bull semen of satisfactory quality in terms of nonreturn rate was being discarded by routine laboratory tests. The results have shown that this was the case and provide information by which limits of the laboratory tests may be adjusted to avoid discarding good semen in the future. However, for maximum effect the A.I. industry should decide (a) 
Table 3. The percentage distribution of 9 morphological classes of spermatozoa, distinguished according to the presence $(+)$ or absence $(-)$ of ultrastructural features of the plasma membrane and acrosome in fresh, cooled and frozen semen from 6 bulls

\begin{tabular}{|c|c|c|c|c|c|c|c|c|c|c|}
\hline & & \multicolumn{9}{|c|}{ Class } \\
\hline & & 1 & 2 & 3 & 4 & 5 & 6 & 7 & 8 & 9 \\
\hline \multicolumn{11}{|l|}{ Plasma membrane } \\
\hline Intact & & + & + & + & + & - & - & - & - & - \\
\hline Broken or lost & & - & - & - & - & + & + & + & + & + \\
\hline \multicolumn{11}{|l|}{ Acrosome } \\
\hline Swollen & & - & + & + & + & - & - & + & + & + \\
\hline Vesiculated & & - & - & + & + & + & - & - & - & - \\
\hline Vacuolated & & - & - & - & - & - & - & - & + & - \\
\hline Loss of outer membrane & & - & - & - & + & - & - & - & - & + \\
\hline Loss of contents & & - & - & - & - & + & - & - & - & + \\
\hline \multicolumn{11}{|l|}{ Fresh semen } \\
\hline Bult 1 & & 96 & $\mathbf{0}$ & 0 & 0 & $\mathbf{0}$ & 1 & $\mathbf{0}$ & 1 & 2 \\
\hline 2 & & 70 & 24 & $\mathbf{0}$ & $\mathbf{l}$ & 1 & $\mathbf{0}$ & 1 & $\mathbf{0}$ & 3 \\
\hline 3 & & 67 & 3 & 9 & 0 & $\mathbf{0}$ & 0 & 4 & 7 & 10 \\
\hline 4 & & 79 & $\mathbf{0}$ & 2 & $\mathbf{0}$ & $\mathbf{0}$ & 3 & 4 & 3 & 9 \\
\hline 5 & & 86 & 0 & 1 & $\mathbf{0}$ & 1 & 2 & 1 & 6 & 3 \\
\hline 6 & & 18 & 12 & 3 & 4 & 5 & 1 & 2 & 5 & 50 \\
\hline \multicolumn{11}{|l|}{ Semen cooled to $5^{\circ} \mathrm{C}$} \\
\hline Bull 1 & & 23 & 62 & 0 & 0 & $\mathbf{0}$ & 0 & 8 & 1 & 6 \\
\hline 2 & & 21 & 63 & 5 & 4 & $\mathbf{0}$ & 1 & 3 & $\mathbf{0}$ & 3 \\
\hline 3 & & 6 & 30 & 4 & 11 & 6 & 0 & 7 & 6 & 30 \\
\hline 4 & & 26 & 40 & 3 & 3 & $\mathbf{0}$ & $\mathbf{0}$ & 6 & 5 & 17 \\
\hline 5 & & 7 & 74 & $\mathbf{0}$ & 0 & $\mathbf{0}$ & 0 & 7 & 1 & 11 \\
\hline 6 & & 2 & 34 & 3 & 2 & 2 & 0 & 11 & 3 & 43 \\
\hline Frozen semen & $\begin{array}{c}\text { 112-day } \\
\text { non-return } \%\end{array}$ & & & & & & & & & \\
\hline Bull 1 & $60 \cdot 6$ & 9 & 31 & 3 & 2 & 0 & 1 & 12 & 17 & 25 \\
\hline 2 & $63 \cdot 3$ & 6 & 19 & 1 & 2 & 1 & 13 & 6 & 12 & 40 \\
\hline 3 & $58 \cdot 5$ & 9 & 15 & 1 & $\mathbf{0}$ & $\mathbf{0}$ & 9 & 12 & 11 & 43 \\
\hline 4 & $63 \cdot 6$ & 15 & 14 & 1 & 6 & 1 & 4 & 4 & 9 & 46 \\
\hline 5 & $63 \cdot 4$ & 20 & 30 & 7 & 0 & $\mathbf{0}$ & 4 & 8 & 6 & 25 \\
\hline 6 & $15 \cdot 0$ & 0 & $\mathbf{0}$ & 1 & 1 & 2 & 0 & 2 & 6 & 88 \\
\hline
\end{tabular}

what is an unacceptable non-return rate; and (b) whether it aims to discard as little as possible of semen of high genetic merit or to achieve a compromise between attaining the highest non-return rate and discarding a larger number of semen samples.

The results of Exp. 1 on fresh and frozen semen might have been expected to yield results similar to those of the previous study by Bishop et al. (1954). However, the small number of semen samples used and the narrow distribution of the non-return data provided results of little value. For example, the motility meter (Test $D$ ) was the best test for semen used after freezing but the worst for semen used fresh, even though the test was carried out on raw undiluted semen before it was divided into two batches for the preparation of fresh and frozen inseminates. Furthermore, positive rather than negative correlations were obtained for the $\%$ of dead spermatozoa and the non-return rate obtained by the use of either fresh or frozen semen. These results led to no confidence in the laboratory tests and indicated that semen should not be discarded on this basis. Nevertheless, the samples used were from a small number of bulls selected for A.I. from which poor semen production would not be anticipated. The question was then posed that if, by some change in the animal's health, very poor semen were obtained from a bull at an A.I. Centre would the laboratory tests reveal its inadequacy? Therefore a larger number of bulls, some of which were known to have a low non-return rate, were selected for Exp. 2. The results showed that in most cases very poor quality semen which gave a non-return rate of $<45 \%$ would be revealed and discarded by the laboratory tests used routinely for semen evaluation. 
This study shows that, at this time, the best evaluation of frozen semen may be achieved by measuring the motility of the sample before processing and the \% of dead and morphologically abnormal cells. Bishop et al. (1954) came to the same conclusion for evaluation of fresh semen. By the combination of three such tests, $60 \%$ of the non-return variance was accounted for. This was not high and a new semen test with a better regression with non-return rate is evidently required. However, the true contribution of the semen and the variation in the non-return rate is unknown; $60 \%$ may be the maximum proportion attributable solely to the male and the rest may be due to variations in the female. Until this information is available the assessment of new methods of semen evaluation will be difficult.

Non-return values were correlated with all measures of motility. Nevertheless, it must be stressed that the subjective motility measurements were carried out by trained personnel with experience in viewing semen under a microscope. If such personnel were not available it would be advisable to use the motility meter although this instrument cannot be used for diluted semen. For export, or import, for which only frozen samples can be used, sperm motility would have to be assessed subjectively (Test G) and these results show that only those samples in which motility after thawing is less than $20 \%$ contribute to a reduction in the average non-return rate. A satisfactory alternative to subjective motility assessment after freezing would be by calorimetry (Test $\mathrm{L}$ ) but the instrument required is expensive. Many of the motility tests and dead or abnormal cell tests were inter-correlated, i.e. a dead spermatozoon or one with certain tail abnormalities was also an immotile spermatozoon. The presence of the cytoplasmic droplet on the bull spermatozoon is an indication of immaturity of the cell (Hancock, 1959) and has no causal relationship with death or immotility. This explains why the \% of spermatozoa with anterior droplets (Test $\mathrm{F}(\mathrm{iii})$ ) was so valuable in combination with other tests because it contributed additional information about the semen. In the search for new tests, therefore, emphasis should be laid on testing other aspects of the spermatozoon, such as acrosome integrity (Saacke, 1972; Foulkes \& Watson, 1975), rather than on measuring with greater accuracy characteristics already well monitored.

Although the correlations between the non-return rate at 112 days and the tests used here were relatively high, the regressions were not good, showing that the tests were of little value as a means of predicting non-return value. As in the study of Van Duijn (1971), formulae may be computed by which estimates of the non-return values from a number of semen tests may be determined. However, the $95 \%$ confidence limits of our estimates included almost the whole range of values obtained. What justification is there then for either rejecting a semen sample or rejecting a bull for A.I. on the basis of these tests?

The results of Exp. 2 are of value to illustrate the limit for each test below which semen should be discarded to improve overall A.I. results. For example, lines may be drawn on Text-fig. 3 to represent acceptable limits of non-return values and $\%$ motility in saline (Test $\mathrm{C}$ ). Thus, if all semen samples having a motility of $<20 \%$ were discarded and a non-return rate of $50 \%$ were acceptable, any samples in the hatched area bounded by lines $x_{1}$ and $y_{1}$ (Text-fig. 3 ) would be discarded even though the nonreturn rate would have been acceptable. This amounts to one sample outside the confidence interval that would have been wasted unnecessarily. By changing the limits to $60 \%$ non-return and $40 \%$ motility (lines $x_{2}$ and $y_{2}$, Text-fig. 3), we can see that the number of good samples wasted has increased to four. However it is generally more important from the farmer's point of view to prevent the use of inferior semen and so acceptance limits could be defined. In this experiment a lower limit of $40 \%$ would exclude all semen with a non-return rate less than $50 \%$ and yet would waste less than $10 \%$ of good samples.

That statistically highly significant differences were revealed between bulls for non-return value, $\%$ motility in saline, $\%$ dead spermatozoa, $\%$ abnormal spermatozoa, \% spermatozoa with anterior droplets and $\%$ motility after freezing raises doubts as to the validity of applying one standard to all bulls. It would seem that the most satisfactory method of testing a bull's semen quality for A.I. would be to construct a regression line for that bull by using a number of his semen samples as long as they satisfied the minimum limit of laboratory tests. This regression may then be used to monitor that bull's performance during his stay at the A.I. centre. Differences of statistical significance between breeds, particularly between Friesians and Herefords, were demonstrated for motility measurements 
and for sperm head abnormalities. Since no breed differences were apparent in non-return rate this suggests that different standards may have to be applied to different breeds.

The ultrastructural studies were carried out on only a few samples. The value of electron microscopy as a method of semen evaluation is limited by the expense and the time-consuming procedures involved. However, recent work has shown that transmission electron microscopy (Morstin \& Courot, 1974) and scanning electron microscopy (Lacy, Pettitt, Pettitt \& Martin, 1974) of spermatozoa may be used to detect sub-fertility in the bull and infertility in man.

We acknowledge the assistance of the staff of the Reading Cattle Breeding Centre and of Mr A. J. Cliffe, and Mr S. V. Morant of the National Institute for Research in Dairying.

\section{References}

Bishop, M.W.H., Campbell, R.C., Hancock, J.L. \& Walton, A. (1954) Semen characteristics and fertility in the bull. J. agric. Sci., Camb. 44, 227-248.

Foulkes, J.A. \& Watson, P.A. (1975) Hyaluronidase activity in seminal plasma as a method of assessing bull sperm integrity. J. Reprod. Fert. 43, 349-353.

Glover, F.A. (1968) Physical method of measuring the motility of bull spermatozoa. Nature, Lond. 219 1263-1264.

HANCOCK, J.L. (1956) The morphology of boar spermatozoa. Jl R. microsc. Soc. 76, 84-97.

Hancock, J.L. (1959) Morphological characteristics of spermatozoa and fertility. Int. J. Fert. 4, 347-359.

Jones, R.C. \& MARTIN, I.C.A. (1973) The effects of dilution, egg yolk and cooling to $5^{\circ} \mathrm{C}$ on the ultrastructure of ram spermatozoa. J. Reprod. Fert. 35, 311-320.

Lacy, D., Petritt, A.J., Petritt, J.M. \& Martin, B.S. (1974) Application of scanning electron microscopy to semen analysis of the sub-fertile man utilising data obtained by transmission electron microscopy as an aid to interpretation. Micron 5, 135-173.

Morstin, J. \& Courot, M. (1974) Ultrastructure des spermatozoides de taureaux de différente fécondance morphologie ultrastructurale, glycoprotéines acrosomiques et membranaires, charges négatives de surface. Annls Biol. anim. Biochim. Biophys. 14, 581590.

SAACKe, R.G. (1972) Semen quality tests and their relationship to fertility. Proc. 4th Tech. Conf. A.I. \& Reprod., N.A.A.B., Chicago pp. 22-27.

Stewart, D.L., O'Hagan, C. \& Glover, F.A. (1972) The prediction of the fertility of bull semen from laboratory tests. Proc. 7 th Int. Congr. Anim. Reprod. \& A.I., Munich 2, 1280-1283.

Van DuIJn, C., JR (1971) Beziehungen zwischen den Eigenschaften des Samens und der Befruchtungsfahigkeit. Dt. tierärztl. Wschr. 78, 73-148.

Received 25 November 1975 